\title{
PENGELOLAAN RISIKO TABUNGAN EMAS DI PEGADAIAN SYARIAH
}

\author{
Ana Zuliatin Nadhiroh \\ Mahasiswa Program Studi S1 Ekonomi Islam-Fakultas Ekonomi dan Bisnis-Universitas Airlangga \\ Email: ana.zuliatin-13@feb.unair.ac.id \\ Noven Suprayogi \\ Departemen Ekonomi Syariah-Fakultas Ekonomi dan Bisnis-Universitas Airlangga \\ Email: noven.suprayogi25@gmail.com
}

\begin{abstract}
:
Islamic pawnshop in Blauran is the official goverment institutions that do funding in the form of lending with the basis of legal pawn based on Islamic Shariah. Islamic pawnshop has many products and among is gold saving. This research uses descriptive qualitative approach. This research uses case study method.Technique of data collection is done by participant observation, semiterstruktur interview, and documentation. The result of this research can be concluded that blueprint pawnshop implements risk management of gold saving product with three stages, that is, risk identification by identifying any risks attached to gold saving by tracing the cause of the risk, evaluation and measurement of risk by making frequency and significance matrix and risk management by doing risk mitigation such as there are institutions of audit and there are promote from Islamic pawnshop.
\end{abstract}

Keywords: Gold Saving, Islamic pawnshop, Risk management

\section{PENDAHULUAN}

\section{Latar Belakang}

Yuliana (2010:2) menjelaskan bahwa investasi adalah sebagai komitmen atas jumlah dana atau sumber daya lainnya yang dilakukan pada saat ini, dengan tujuan memperoleh sejumlah keuntungan dimasa datang.

Menurut Yuliana (2010:17) menjelaskan prinsip-prinsip ekonomi Islam dalam berinvestasi yang harus diperhatikan oleh pelaku investasi baik investor maupun lembaga, yaitu:

1 Tidak mencari rizki dalam hal yang haram, baik dari segi zatnya maupun cara mendapatkannya, serta tidak digunakan untuk hal-hal yang haram.

2 Tidak mendzalimi dan didzalimi.

3 Keadilan pendistribusian kemakmuran.

4 Transaksi dilakukan atas dasar suka sama suka (ridha).
5 Tidak ada unsur riba, maysir, dan gharar, seperti yang dijelaskan dalam firman Allah Al-Imron : 130

Artinya: "Hai orang-orang yang beriman, janganlah kamu memakan riba dengan berlipat ganda dan bertakwalah kamu kepada Allah supaya kamu mendapat keberuntungan."

Tabungan emas adalah layanan pembelian dan penjualan emas dengan fasilitas titipan dengan harga yang terjangkau. Layanan ini memberikan kemudahan kepada masyarakat untuk berinvestasi emas (www.pegadaian.co.id).

Perkembangan tabungan emas bergerak kearah positif, setiap bulannya mengalami peningkatan, seperti yang terdapat pada tabel di bawah ini:

\footnotetext{
[1]JurnalinimerupakanbagiandariSkripsi Ana ZuliatinNadhiroh NIM 041311433162 yang diujipadatanggal 10 Agustus 2017
} 
Nadhiroh, et al/JurnalEkonomiSyariahTeoridanTerapan Vol. 5 No. 12 Desember 2018: 987-997;

PENGELOLAAN RISIKO TABUNGAN EMAS DI PEGADAIAN SYARIAH

Tabel 1

Perkembangan Tabungan Emas Di

Pegadaian Syariah Se-Indonesia

Tahun 2017

\begin{tabular}{|c|c|c|c|}
\hline No. & Bulan & $\begin{array}{c}\text { Total } \\
\text { nasabah }\end{array}$ & $\begin{array}{c}\text { Jumlah } \\
\text { emas } \\
\text { disimpan } \\
\text { (gr) }\end{array}$ \\
\hline 1. & $\begin{array}{c}\text { Januari } \\
2017\end{array}$ & 103.107 & $\begin{array}{c}107.388,76 \\
74\end{array}$ \\
\hline 2. & $\begin{array}{c}\text { Februari } \\
2017\end{array}$ & 106.082 & $\begin{array}{c}112.757,15 \\
23\end{array}$ \\
\hline 3. & $\begin{array}{c}\text { Maret } \\
2017\end{array}$ & 109.980 & $\begin{array}{c}116.895,43 \\
50\end{array}$ \\
\hline 4. & $\begin{array}{c}\text { April } \\
2017\end{array}$ & 114.260 & $\begin{array}{c}124.096,46 \\
94\end{array}$ \\
\hline
\end{tabular}

Sumber : Pegadaian Syariah Blauran (diolah)

Prosedur tabungan emas yaitu membuka rekening tabungan emas di pegadaian syariah dengan melampirkan fotocopy identitas diri yang masih berlaku, mengisi formulir pembukaan rekening dengan membayar sebesar Rp 10.000 dan biaya fasilitas titipan selama setahu Rp 30.000, proses pembelian emas dapat dilakukan Rp5.790, untuk pembelian dikonversi menjadi emas sampai 4 digit dibelakang koma. Selisihnya sebagai dana kepedulian sosial (www.pegadaian.co.id).

Apabila membutuhkan dana tunai saldo titipan nasabah dapat dijual kembali ke pegadaian dengan minimal penjualan 1 gram dan nasabah menerima vang tunai sebesar Rp 549.000. apabila menghendaki emas batangan nasabah dapat melakukan order cetak dengan pilihan keping emas 1 gram, 2 gram, 5 gram, 10 gram, 25 gram, 50 gram dan 100 gram (www.pegadaian.co.id). Berikut buku rekening tabungan emas nasabah:

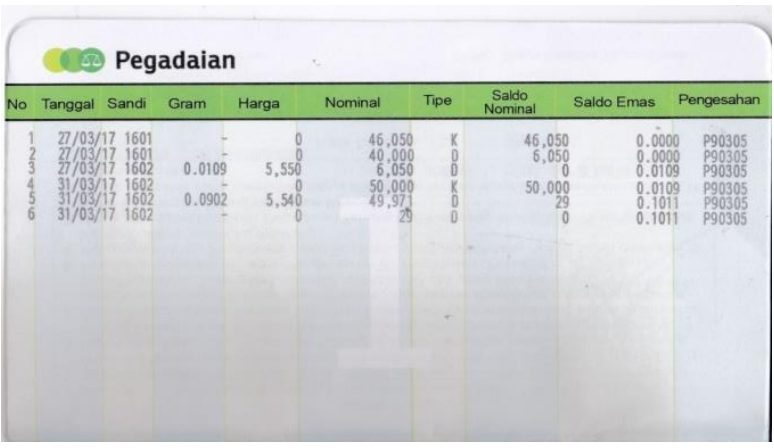

Sumber : Dokumentasi peneliti

\section{Gambar 1}

\section{Buku Rekening Tabungan Emas}

Risiko adalah suatu ketidakpastian yang merupakan sunnatullah yang dihadapi manusia. Dalam surat al-Luqman ayat 34:

"Sesungguhnya Allah, hanya pada sisi-Nya sajalah pengetahuan tentang hari Kiamat; dan Dia-lah yang menurunkan hujan, dan mengetahui apa yang ada dalam rahim. dan tiada seorangpun yang dapat mengetahui (dengan pasti) apa yang akan diusahakannya besok. Tiada seorangpun yang dapat mengetahui di bumi mana Dia akan mati. Sesungguhnya Allah Maha mengetahui lagi Maha Mengenal."

Berdasarkan uraian diatas dapat diketahui risiko yang mungkin melekat pada tabungan emas adalah risiko likuiditas, risiko imbal hasil, dan risiko operasional. Pegadaian syariah perlu melakukan manajemen risiko. Manajemen risiko adalah serangkaian metodologi dan prosedur yang digunakan untuk mengidentifikasi, mengukur, memantau dan mengendalikan risiko 
Nadhiroh, et al/JurnalEkonomiSyariahTeoridanTerapan Vol. 5 No. 12 Desember 2018: 987-997;

PENGELOLAAN RISIKO TABUNGAN EMAS DI PEGADAIAN SYARIAH

yang timbul dari seluruh kegiatan usaha perusahaan (Peraturan OJK, 2016:3). Manajemen risiko yaitu seperangkat kebijakan, prosedur yang lengkap yang dipunyai organisasi, untuk mengelola, memonitor dan mengendalikan eksposur organisasi terhadap risiko (Hanafi,2014:18). Langkah-langkah manajemen risiko menurut Hanafi (2014:8)

1 Identifikasi risiko

2 Evaluasi dan pengukuran risik

3 Pengelolaan risiko

Pengelolaan risiko merupakan bentuk usaha manusia. Sebab manusia diperintahkan untuk selalu berusaha karena sesuatu tidak terjadi begitu saja namun harus diusahakan, sebagaimana pada surat Ar-Rad ayat 11:

"Bagi manusia ada malaikatmalaikat yang selalu mengikutinya bergiliran, di muka dan di belakangnya, mereka menjaganya atas perintah Allah. Sesungguhnya Allah tidak merobah keadaan sesuatu kaum sehingga mereka merobah keadaan yang ada pada diri mereka sendiri. dan apabila Allah menghendaki keburukan terhadap sesuatu kaum, Maka tak ada yang dapat menolaknya; dan sekali-kali tak ada pelindung bagi mereka selain Dia"(Q.S 13:11)

Berdasarkan uraian diatas peneliti tertarik untuk melakukan penelitian yang berjudul "Pengelolaan Risiko Tabungan Emas di Pegadaian Syariah"

\section{RUMUSAN MASALAH}

Berdasarkan latar belakang masalah yang telah diuraikan diatas, maka permasalahan yang dapat dirumuskan adalah: bagaimana manajemen risiko tabungan emas di Pegadaian Syariah Blauran Surabaya.

\section{TUJUAN}

Adapun tujuan penelitian adalah untuk mengetahui dan menganalisis manajemen risiko pada produk tabungan emas yang harus dilakukan oleh Pegadaian Syariah cabang Blauran Surabaya.

\section{LANDASAN TEORI}

\section{Konsep Pegadaian}

Menurut Syafe'i (2001:159) gadai dalam bahasa Arab disebut rahn. Secara bahasa (etimologi), rahn berarti tetap dan lama, yakni tetap atau berarti al-habsu walluzuum (pengekangan dan keharusan).rahn adalah suatu akad kontrak perjanjian rahn yang menjadikan barangnya sebagai jaminan atas sejumlah dana hutang yang diperoleh peminjam dana dari pegadaian syariah.

Konsep pegadaian syariah harus terhindar riba, gharar, dan maysir, seperti surat ArRum ayat 39:

"Dan sesuatu Riba (tambahan) yang kamu berikan agar Dia bertambah pada harta manusia, Maka Riba itu tidak menambah pada sisi Allah. dan apa yang kamu berikan berupa zakat yang kamu maksudkan untuk mencapai keridhaan Allah, Maka (yang berbuat demikian) Itulah orang-orang yang melipat gandakan (pahalanya)."

$$
\text { Mekanisme pegadaian syariah }
$$

menurut Soedarsono (2008:178) adapun teknis pegadaian sayriah adalah sebagai berikut:

1 Nasabah menjaminkan barang kepada pegadaian syariah untuk menadapatkan pembiayaan. 
Nadhiroh, et al/JurnalEkonomiSyariahTeoridanTerapan Vol. 5 No. 12 Desember 2018: 987-997;

\section{PENGELOLAAN RISIKO TABUNGAN EMAS DI PEGADAIAN SYARIAH}

Kemudian menaksir barang jaminan untuk dijadikan dasar dalam pemberikan pembiayaan.

2 Pegadaian syariah dan nasabah menyetujui akad gadai, akad ini mengenai berbagai hal, seperti kesepakatan biaya administrasi, tarif jasa simpan, pelunasab dan sebagainya

3 Pegadaian menerima biaya administrasi dibayar diawal transaksi sedangkan untuk jasa simpan disaat pelunasan utang

4 Nasabah melunasi barang yang digadaikan menurut akad, pelunasan penuh, ulang gadai, angsuran atau sebus sebagian.

\section{Investasi Emas}

Menurut Suryomurti (2011:20) dalam bukunya menyebutkan manusia menyukai benda berharga yang disebut dengan logam mulia seperti emas dan perak. Emas dan perak dapat digunakan untuk perhiasan dan aksesoris yang digunakan dalam kehidupan sehari-hari. Surat AlImron ayat 14 Allah menjelaskan bahwa:
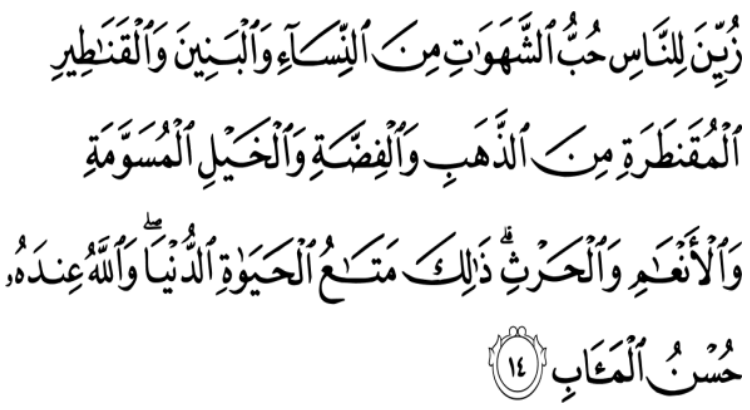

Zuyyina lin-nas̄i hubbusy-syahawałi minan-nisa'i wal-banina wal-qanațiil muqantarati minaz-zahabi walfiddati wal-khailil musawwamati walan'ami wal-hars' zatika mata'ul hayatid-dunya' wallahu' 'indahu husnul-ma'ab.

" Dijadikan indah pada (pandangan) manusia kecintaan kepada apa-apa yang diingini, Yaitu: wanita-wanita, anak-anak, harta yang banyak dari jenis emas, perak, kuda pilihan, binatangbinatang ternak dan sawah ladang. Itulah kesenangan hidup di dunia, dan di sisi Allah-lah tempat kembali yang baik (surga)."

Menurut Quthb dalam tafsir fi zhilalil qur'an menyebutkan surat diatas telah dijelaskan bahwa wanita dan anak-anak merupakan sesuatu yang dicintai dan dinginkan oleh manusia. Hak ini beriringan dengan harta yang banyak berupa emas dan perak. Bukan hanya keinginan namun juga ada unsur lain yaitu kerakusan untuk menimbun emas dan perak. Benda berharga seperti emas dan perak merupakan salah satu kesenangan hidup didunia dimana kesenangan tersebut akan menimbulkan lalai dengan terjadinya penimbunan emas dan perak sehingga Allah memperingatkannya pada surat At-Taubah ayat 34 yang berbunyi :

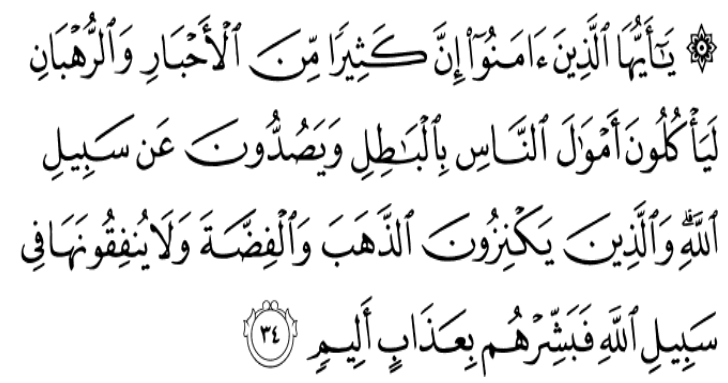

$\mathrm{Ya}^{-}$ayyuhal-lazina àmanu' inna kasiram minal-ahbarìi war-ruhbañi 
Nadhiroh, et al/JurnalEkonomiSyariahTeoridanTerapan Vol. 5 No. 12 Desember 2018: 987-997;

PENGELOLAAN RISIKO TABUNGAN EMAS DI PEGADAIAN SYARIAH

laya'kuluña amwatan-nas̄i bil-bațili wa yașudduña 'an sabitillah, wallazina yaknizunaz zahaba walfiddata wa la yunfiquñaha fi $^{-}$ sabiillahi fa basysyirhum bi'azabin alim.

"Hai orang-orang yang beriman, Sesungguhnya sebahagian besar dari orang-orang alim Yahudi dan rahib-rahib Nasrani benar-benar memakan harta orang dengan jalan batil dan mereka menghalanghalangi (manusia) dari jalan Allah. dan orang-orang yang menyimpan emas dan perak dan tidak menafkahkannya pada jalan Allah, Maka beritahukanlah kepada mereka, (bahwa mereka akan mendapat) siksa yang pedih."

Dijelaskan pada ayat diatas bahwa larangan menyimpan emas dan perak jika tidak mengeluarkan zakat atas emas dan perak tersebut. Hukuman atas penimbunan emas dan perak dari Allah adalah siksa yang pedih. Jika dikaitkan dengan investasi emas, maka jika berinvestasi emas dianjurkan untuk mengeluarkan zakat atas investasi emas tersebut. Seseorang yang memiliki emas setidaknya sebesar 20 dinar emas 185 gram) selama setahun wajib mengeluarkan zakat sebesar 2,5\% dari jumlah emasnya (www.wikipedia.org). Kondisi tersebut disebabkan karena harta adalah hiasan yang mengandung fitnah. Seseorang akan rela melakukan apapun untuk mendapatkan harta, meskipun melalui jalan yang tidak baik demi kesenangan duniawi.

\section{Risiko}

Menurut peraturan otoritas jasa keuangan nomor 65 /pojk.03/2016 tentang penerapan manajemen risiko bagi bank umum syariah dan unit usaha syariah menyebutkan beberapa risiko yang dapat dialami pegadaian syariah adalah sebagai berikut:

1 Risiko kredit adalah risiko akibat kegagalan nasabah atau pihak lain dalam memenuhi kewajiban kepada Bank sesuai dengan perjanjian yang disepakati, termasuk risiko kredit akibat kegagalan debitur, risiko konsentrasi kredit, counterparty credit risk, dan settlement risk.

2 Risiko pasar adalah risiko pada posisi neraca dan rekening administratif akibat perubahan harga pasar, antara lain Risiko berupa perubahan nilai dari aset yang dapat diperdagangkan atau disewakan.

3 Risiko likuiditas adalah risiko akibat ketidakmampuan pegadaian untuk memenuhi kewajiban yang jatuh tempo dari sumber pendanaan arus kas dan/atau dari aset likuid berkualitas tinggi yang dapat diagunkan, tanpa mengganggu aktivitas dan kondisi keuangan pegadaian.

4 Risiko operasional adalah risiko kerugian yang diakibatkan oleh proses internal yang kurang memadai, kegagalan proses internal, kesalahan manusia, kegagalan sistem, dan/atau adanya kejadian eksternal yang 
Nadhiroh, et al/JurnalEkonomiSyariahTeoridanTerapan Vol. 5 No. 12 Desember 2018: 987-997;

PENGELOLAAN RISIKO TABUNGAN EMAS DI PEGADAIAN SYARIAH

mempengaruhi

operasional

pegadaian.

5 Risiko hukum adalah risiko akibat tuntutan hukum dan/atau kelemahan aspek yuridis.

6 Risiko reputasi41 adalah risiko akibat menurunnya tingkat kepercayaan pemangku kepentingan (stakeholder) yang bersumber dari persepsi negatif terhadap pegadaian.

7 Risiko strategi adalah risiko akibat ketidaktepatan dalam pengambilan dan/atau pelaksanaan suatu keputusan stratejik serta kegagalan dalam mengantisipasi perubahan lingkungan bisnis.

8 Risiko kepatuhan syariah adalah risiko akibat pegadaian tidak mematuhi dan/atau tidak melaksanakan peraturan perundang-undangan dan ketentuan yang berlaku serta prinsip syariah.

9 Risiko imbal hasil (Rate of Return Risk) adalah risiko akibat perubahan tingkat imbal hasil yang dibayarkan pegadaian kepada nasabah, karena terjadi perubahan tingkat imbal hasil yang diterima Bank dari penyaluran dana, yang dapat mempengaruhi perilaku nasabah dana pihak ketiga Bank.

10 Risiko investasi (Equity Investment Risk) adalah risiko akibat pegadaian ikut menanggung kerugian usaha nasabah yang dibiayai dalam pembiayaan berbasis bagi hasil baik yang menggunakan metode net revenue sharing maupun yang menggunakan metode profit and loss sharing.

Menurut Khan dan Habib Ahmed ( 2008:124). menyebutkan terdapat risiko unik yang dapat menambah kemungkinan terjadinya risiko lain, yaitu fiduciary risk, withdrawal risk, dan displaced commercial risk. Fiduciary risk adalah risiko yang secara hukum bertanggung jawab atas pelanggaran kontrak investasi baik ketidaksesuaiannya dengan ketentuan syariah atas salah kelola terhadap dana investor. Withdrawal risk adalah risiko penarikan dana. Risiko ini muncul akibat keuntungan atau return yang diterima oleh investor atau deposan lebih rendah dari tingkat return yang diberikan oleh rival kompetitornya. Displaced commercial risk adalah transfer risiko simpanan pegadaian ke nasabah. Risiko ini muncul karena pegadaian mendapatkan tekanan untuk mendapatkan profit namun justru harus memberikan sebagian profitnya kepada nasabah atau deposan akibat rendahnya return yang didapatkan oleh nasabah.

\section{Pengelolaan Risiko}

Tahapan pengelolaah risiko, pertaman : Identifikasi risiko adalah kegiatan mengidentifikasi semua risiko usaha yang dihadapi lembaga keuangan syariah dan konvensional (Kasidi,2010:8). Tahap ini merupakan tahapan awal untuk lebih mengetahui risiko apa saja yang terjadi pada perusahaan, sehingga dapat melakukan manajemen atau pengelolaan lebih dini. Kedua, Evaluasi dan Pengukuran risiko adalah kegiatan untuk 
Nadhiroh, et al/JurnalEkonomiSyariahTeoridanTerapan Vol. 5 No. 12 Desember 2018: 987-997;

PENGELOLAAN RISIKO TABUNGAN EMAS DI PEGADAIAN SYARIAH

menilai bagian-bagian yang diperkirakan akan menjadi penyebab terjadinya suatu kerugian (Kasidi, 2010:8). Ketiga, Langkah terakhir setelah proses evaluasi dan pengukuran risiko adalah pengelolaan risiko. Risiko harus dikelola, jika dibiarkan maka perusahaan harus menanggung dampak yang serius untuk masa depan perusahaan, misalnya dapat berdampak kerugian hingga kebangkrutan.

\section{METODE PENELITIAN}

\section{Pendekatan Penelitian}

Pendekatan penelitian yang digunakan pada penelitian ini adalah pendekatan kualitatif deskriptif. Pada penelitian ini peneulis menggunakan strategi studi kasus (Yin. 2009:8).

\section{Ruang lingkup}

Sugiyono(2014:223) Ruang lingkup penelitian akan dibentuk berdasarkan rumusan masalah yang akan dijawab. Ruang lingkup penelitian ini terbatas bagaimana pengelolaan risiko tabungan emas di Pegadaian Syariah Blauran Suarabaya

\section{Jenis dan Sumber Data}

\section{Data primer}

Pada penelitian ini, data primer didapatkan dengan melakukan wawancara kepada pihak pegadaian syariah. Wawancara dilakukan dengan kepala cabang dan pegawai pegadaian syariah (Sugiyono, 2012:80).

\section{Data sekunder}

Data sekunder pada penelitian ini berasal dari hasil dokumentasi berupa gambar atau foto, brosur, rekaman wawancara, situs internet, data tabungan emas dan data pendukung lainnya seperti jurnal, artikel dan buku-buku tentang manajemen risikonya.

\section{Teknik Pengumpulan Data}

Teknik yang digunakan dalam penelitian lapangan adalah:

\section{Obervasi}

MenurutSugiyono (2014:226) pada penelitian ini peneliti memilih observasi partisipatif yaitu, peneliti ikut terlibat dengan kegiatan sehari-hari orang yang diamati. Peneliti ikut berpartisipasi dalam kegiatan sehari-hari sebagai mahasiswa magang sambil melakukan pengamatan dan peneliti juga ikut serta menjadi nasabah tabungan emas sehingga dapat merasakan suka dukanya sebagai nasabah.

2 Wawancara

Menurut Satori danKomariah(2013:133) langkah yang dilakukan peneliti adalah wawancara semiterstrutur, yaitu teknik pengumpulan data yang pelaksanaanya lebih bebas untuk menemukan permasalahan secara lebih terbuka, dimana informan diminta mengeluarkan pendapat dan ide-idenya (Sugiyono, 2014:233). Jumlah informan dalam penelitian ini dibatasi sesuai kebutuhan peneliti yaitu Kepala Cabang Pegadaian Syariah Blauran dan Pegawai Pegadaian Syariah Blauran (Kasir dan Customer Service Pegadaian Syariah Blauran Surabaya).

3 Dokumentasi 
Nadhiroh, et al/JurnalEkonomiSyariahTeoridanTerapan Vol. 5 No. 12 Desember 2018: 987-997;

PENGELOLAAN RISIKO TABUNGAN EMAS DI PEGADAIAN SYARIAH

Jenis dokumen untuk memperoleh data dapat berupa gambar, brosur, hasil wawancara yang menunjang hasil wawancara (Satori dan Komariah,2013:148).

\section{Teknik Validasi}

BerdasarkanSugiyono

(2014:241)

Penelitian ini menggunakan metode triangulasi sumber. Triangulasi dengan sumber berarti membandingkan dan mengecek balik derajat kepercayaan suatu informasi yang diperoleh melalui waktu dan alat yang berbeda dalam metode kualitatif.

\section{Teknik Analisis Data}

Teknik analisis data yang digunakan dalam penelitian ini berdasarkan teori yang dikemukakan Sugiyono (2014:243), yaitu:

a Analisis domain

Analisis domain pada umunya dilakukan untuk memperoleh gambaran yang umum dan menyeluruh tentang situasi sosial yang diteliti atau objek penelitian. Dalam penelitian ini informasi yang diperoleh belum mendalam. Analisis domain terhadap proses manajemen risiko pada produk tabungan emas di pegadaian syariah.

b Analisis taksonomi

Setelah melakukan analisis domai, sehingga ditemukan domain-domain atau kategori dari situasi sosial tertentu, maka selanjutnya domain yang dipilih ditetapkan sebagai fokus penelitian dan perlu diperdalam lagi. Dengan demikian domain yang telah ditetapkan pleh peneliti dapat diuraikan secara lebih rinci dan mendalam melalui analisis taksonomi.

IV. HASIL DAN PEMBAHASAN

Mekanisme tabungan emas

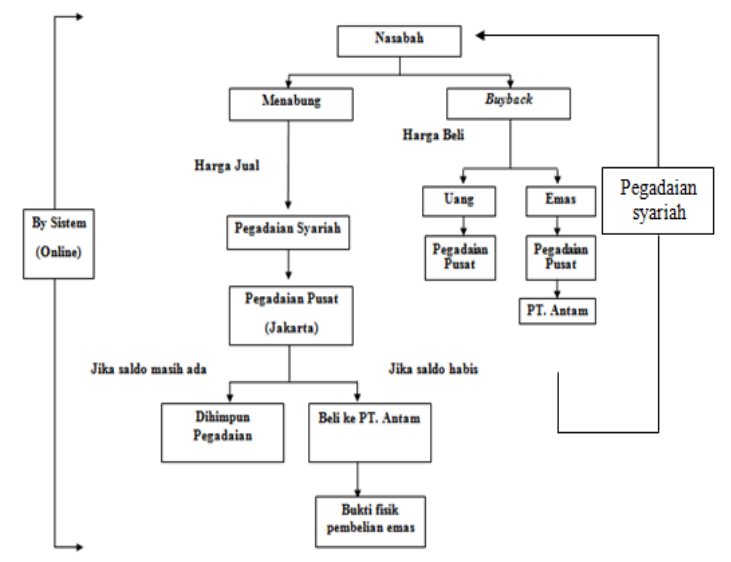

Gambar 1

\section{Proses Bisnis Tabungan Emas}

Sumber: hasilwawancara

Proses bisnis tabungan emas diatas menjelaskan alur tabungan emas yang berawal dari ketika nasabah menabung menggunakan harga jual ke pegadaian syariah. tabungan emas dikumpulkan seIndonesia lalu dikirim ke pegadaian pusat di Jakarta. Di pegadaian pusat terdapat tim yang namanya tim pengelola stock emas. Tim tersebut bertugas untuk mengelola stock tabungan emas di pegadaian. Ketika pembelian emas ke PT. Antam menunjukkan bahwa saldo stock habis dan pembelian tersebut terdapat bukti fisik pembelian sekian ton dari PT. Antam. Ketika stock masih ada, pihak tim pengelola akan menyimpan vangnya di pegadaian.

Proses pengambilan tabungan emas menggunakan dua pilihan yaitu berupa uang atau emas. Buyback 
Nadhiroh, et al/JurnalEkonomiSyariahTeoridanTerapan Vol. 5 No. 12 Desember 2018: 987-997;

PENGELOLAAN RISIKO TABUNGAN EMAS DI PEGADAIAN SYARIAH

menggunakan harga beli. Nasabah yang akan buyback vang di otorisasikan dari pegadaian pusat. Nasabah yang ingin order emas akan dipesankan dari PT.antam yang otomatis akan mengurangi stock emas pegadaian.

Harga jual dan harga beli terdapat selisih harga. Selisih tersebut dijadikan keuntungan tabungan emas untuk perusahaan. Harga jual dan harga beli ditetapkan oleh pegadaian di pusat.

Nasabah dapat menjual kembali emasnya ke pegadaian syariah. Emas yang diterima oleh pegadaian hanya emas dengan sertifikat dari pegadaian. Nasabah membawa bukti sertifikat emas dan barangnya lalu diserahkan ke pegadaian. Ketika nasabah menjual kembali emasnya menggunakan harga beli yang ditetapkan oleh pegadaian.

Risiko yang melekat pada tabungan emas yaitu:

$\begin{array}{ll}1 & \text { Risiko Reputasi } \\ 2 & \text { Risiko imbal hasil } \\ 3 & \text { withdrawal risk } \\ 4 & \text { Risiko karyawan } \\ 5 & \text { Risiko likuiditas }\end{array}$

Pengukuran risiko dengan menggunakan matriks signifikansi dan frekuensi menghasilkan bahwa risiko reputasi berada pada skala 3 dengan skala high. Hal ini mengakibatkan dapat merusak citra perusahaan. Nasabah komplain ke pegadaian syariah tercatat sekitar 5-11 orang pertama kali saja.
Sehingga dapat diketahui nasabah komplain termasuk skala risiko tinggi.

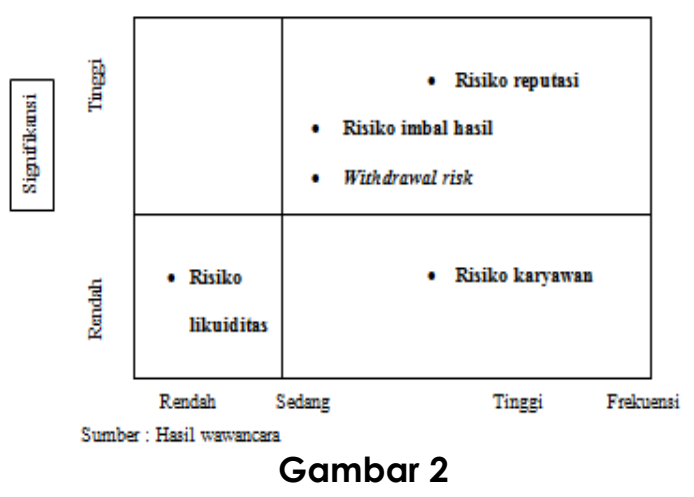

Matriks signifikansi dan frekuensi

Pengelolaan risiko pegadaian syariah (hasil wawancara):

1. Risiko reputasi - menambah saldo tabungan nasabah

2. Risiko karyawan - pendekatan ke pegawai "shodaqoh pegawai"

3. Riisko imbal hasil-withdrawal risk promo kemilau tabungan emas dan gebyar ayo menabung emas

4. Risiko likuiditas - dialihkan ke gadai dan adanya lembaga auditor yaitu kap, ojk, auditor internal guna jika ada penyimpangan akan diketahui secepatnya.

BerdasarkanTabel 1.skala risiko tertinggi adalah risiko reputasi. Wahyudi dkk (2013:29) Risiko reputasi adalah risiko yang terjadi akibat menurunnya tingkat kepercayaan pemangku kepentingan yang bersumber dari persepsi negatif terhadap pegadaian syariah. dampak dari publikasi negatif juga berpengaruhn pada keuntungan yang akan diperoleh, likuiditas dan mempengaruhi harga saham pegadaian syariah yang bersangkutan. Sehingga risiko tersebut perlu dilakukan pengelolaan risiko untuk meminimalisir risiko yang terjadi, terutama 
Nadhiroh, et al/JurnalEkonomiSyariahTeoridanTerapan Vol. 5 No. 12 Desember 2018: 987-997;

PENGELOLAAN RISIKO TABUNGAN EMAS DI PEGADAIAN SYARIAH

risiko reputasi yang dinilai merupakan risiko tertinggi.

Tabel 1

Analisis Penelitian

\begin{tabular}{|c|c|c|}
\hline No. & Analisis Domain & Analisis Taksonomi \\
\hline 1. & Identifikasi Risiko & 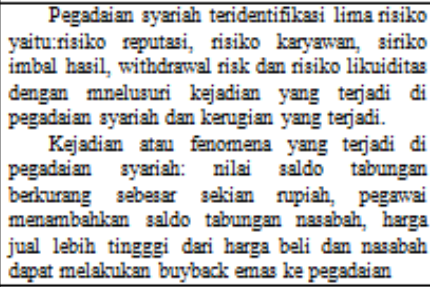 \\
\hline 2. & $\begin{array}{l}\text { Evaluasi dan pengukuran } \\
\text { Risiko }\end{array}$ & $\begin{array}{l}\text { Berdasarkan matriks signifikasnai dan frekunsi } \\
\text { dihasilkan: } \\
1 \text { risiko reputasi yaitu frekuensi dan } \\
\text { signifikansi tinggi } \\
2 \text { risiko imbal hasil dan withdronval risk } \\
\text { frelwensi } 100 \text { dan signifikansi tinggi } \\
3 \text { risiko karyawan ygitu Freluensi } 100 \text { dan } \\
\text { signifikansi rendah } \\
4 \text { Frekunsi dan signifikansi rendah yaitu } \\
\text { risiko likuiditas }\end{array}$ \\
\hline 3. & Pengelolsen Risiko & $\begin{array}{l}\text { Pengelolasn dilakulka dengan mitigasi risiko: } \\
\text { Menambah saldo tabungan nasabah, } \\
\text { Pendeksan ke pegawai "shodagah, } \\
\text { Promo kemilan tabungan emas dan gebyar ayo } \\
\text { menabung emas, } \\
\text { Dialihkan ke gadai dan adanya lembaga suditor } \\
\text { yaitu kap, ojk, auditor intemal guna jika ada } \\
\text { penyimpangan alkan diketahui sacapastnya }\end{array}$ \\
\hline
\end{tabular}

Berdasarkan skala risiko diatas maka pegadaian syariah melakukan pengelolaan yaitu dengan cara :

Startegi manajemen pada produk tabungan emas pegadaian syariah telah melakukan mitigasi risiko yaitu :

1 Menambah saldo tabungan nasabah

2 Pendekatan kepegawai mengenai "shodaqah pegawai"

3 Promo kemilau tabungan emas dan gebyar ayo menabung emas

4 Adanya lembaga auditor dan pengalihan ke produk lain yaitu gadai

\section{SIMPULAN}

Berdasarkan hasil analisis dan interpretasi data yang dilakukan maka dapat diambil kesimpulan pegadaian sayriah melakukan pengelolaan risiko sebagai berikut:

1. Pegadaian Syariah Blauran Surabaya mengidentifikasi risiko tabungan emas dengan melihat dan menelusuri feomena atau kejadian serta kerugian yang ditanggung penelitian. Risiko yang teridentifikasi ada 5 yaitu : risiko reputasi, risiko likuiditas, risiko karyawan, risiko imbal hasil, dan withdrawal risk.

2. Pegadaian Syariah Blauran Surabaya melakukan evaluasi dan pengukuran risiko dengan cara menentukan skala risiko berdasarkan matriks signifikansi dan frekuensi. Hasil yang didapat adalah risiko tertinggi yaitu risiko reputasi.

3. Pegadaian Syariah Blauran Surabaya melakukan pengelolaan risiko dengan cara mitigasi dengan kontrol risiko 
Nadhiroh, et al/JurnalEkonomiSyariahTeoridanTerapan Vol. 5 No. 12 Desember 2018: 987-997;

PENGELOLAAN RISIKO TABUNGAN EMAS DI PEGADAIAN SYARIAH

DAFTAR PUSTAKA

Alqur'an At-Thayyib (Al-qur'an Transliterasi Perkata dan Terjemahan Perkata). Bekasi: Cipta Bagus Segara

Bungin, Burhan. 2001. Metodologi Penelitian Kualitatif. Jakarta: PT. Raja Gapindo Persada

Hadi, A. Chairul. Januari 2012. Menimbang Gadai Emas Sebagai Instrumen Investasi Syariah,, (Online). Jurnal vol IV no, 2), (www.googleschoolar.com didownload tanggal 20 Februari 2017)

Hanafi, Mamduh M. 2014. Manajemen Risiko, Yogyakarta: UPP STIM YKPN

Huda, Nurul dan Mohamad Heykal 2010. Lembaga Keuangan Islam, Jakarta: Kencan Prenada Media Group

Kasidi. 2010. Manajemen Risiko, Bogor: Ghalia Indonesia

Khan, Tariqullah dan Habib Ahmed. 2008. Manajemen Risiko Lembaga Keuangan Syariah, Jakarta: Bumi Aksara

Peraturan Otoritas Jasa Keuangan nomor 65/POJK.03/2016. 2016. PENERA[AN MANAJEMEN RISIKO BAGI BANK UMUM SYARIAH DAN UNIT USAHA SYARIAH. (online) (di download 5 Juli 2017)

PT. Pegadaian Syariah.2016. Tabungan Emas. (Online), (www.pegadaiansyariah.co.id diakses pada tanggal 18 Februari 2017)

Satori, DJm'an dan Aan Komariah. 2009. Metodologi Penelitian Kualitatif, Bandung: Alfabeta

Soedarso, Heri. 2008. Bank dan Lembaga Kevangan Syariah, Yogyakarta: Ekonisia

Sugiyono. 2014. Metode Penelitian Kuantitatif, Kualitatif, dan R\&D, Bandung: CV. Alfabeta

Suryomurti, Wiku. 2011. Super Cerdas Investasi Syariah, Jakarta:QultumMedia

Syafe'i, Rachmad. 2001. Fiqh Muamalah, Bandung: CV. Pustaka Setia

Yin,R. K. 2009. Studi Kasus; Desain dan Metode, Jakarta; Raja Grafindo Persada

Yuliana, Indah. 2010. Investasi Produk Keuangan Syariah. Malang: UIN MALIKI PRESS (ANGGOTA IKAPI MALANG) 